\title{
MITOS DAN BANJIR
}

\author{
Myth and flood \\ Dede Hidayatullah \\ Balai Bahasa Provinsi Kalimantan Selatan \\ Jalan A. Yani km. 32,2 Loktabat Banjarbaru Kalimantan Selatan \\ Pos-el: dayatdh@gmail.com
}

Diterima 11 Oktober $2021 \quad$ Direvisi 15 November $2021 \quad$ Disetujui 18 November 2021

\section{https://doi.org/10.26499/und.v17i2.4047}

Abstrak: Banjir besar melanda bumi Kalimantan Selatan pada awal Januari 2021. Pada saat yang sama, muncul mitos-mitos yang berhubungan dengan banjir besar ini. Penelitian ini bertujuan untuk menguraikan mitos yang muncul pada saat banjir, menjelaskan hubungan antara banjir (lingkungan) dan mitos ini, dan mengungkap penyebab pengaruhnya kepada masyarakat. Ada beberapa tahapan dalam penelitian ini; Pertama, mendata mitos-mitos yang muncul pada saat banjir besar bulan Januari 2021; Kedua, menghubungkan dan mencari sumber mitos itu dari sastra lisan di Kalimantan Selatan. Ketiga, Mengungkapkan makna mitos tersebut. Keempat, menganalisis mitos-mitos dengan menggunakan teori ekokritik Garrard. Kelima, menghubungkan antara mitos dengan masyarakat serta pengaruh mitos itu dalam masyarakat. Ada dua mitos yang muncul pada saat banjir di Kalimantan Selatan, yaitu mitos naga dan mitos keladi. Mitos naga bersumber dari adanya cerita naga penunggu Sungai Barito dalam cerita Asal Mula Sungai Barito dan Sungai Amandit dalam cerita Legenda Lok Sinaga. Sementara itu, mitos keladi berkaitan dengan pamali yang dipercaya orang Banjar. Kedua mitos ini merefleksikan kebudayaan Banjar yang berkaitan dengan isu lingkungan. Mitos naga merupakan kritik sosial terhadap kondisi pegunungan Meratus yang sudah memprihatinkan akibat pertambangan dan perkebunan sawit, sedangkan mitos keladi merupakan kritik untuk bersikap adil terhadap hutan. Kedua mitos ini juga menunjukkan sikap urang Banjar yang tidak menyalahkan alam, lingkungan, dan cuaca, tetapi menyalahkan diri sendiri karena tidak mampu merawat alam.

Kata kunci: mitos, naga, keladi, banjir, dan kerusakan lingkungan

Abstract: A big flood hit South Kalimantan in early January 2021. At the same time, the myths related to this big flood came out. The research objectives are first, to describe the myths that came out during the flood, second, to explain the relationship between floods (environment) and these myths, the third, to reveal the causes of their effects on society. There are several stages in this research; First, to list the myths that emerged during the great flood in January 2021; Second, connecting and finding the source of the myth from oral literature in South Kalimantan. Third, revealing the meaning of the myth. Fourth, analyzing myths using Garrard's eco-critical theory. Fifth, connecting myths with society and the influence of these myths in society. Two myths emerged during the big flood in South Kalimantan, namely the dragon myth and the taro myth. The myth of the dragon comes from the story of the dragon guarding the Barito River in the origin story of the Barito River and the Amandit River in the Legend of Lok Sinaga. The taro myth relates to pamali believed by the Banjar people. These two myths reflect Banjar culture relates to environmental issues. The dragon myth is a social critique of the condition of the Meratus mountains, which is already alarming due to mining and oil palm plantations. Meanwhile, the taro myth is a criticism of being wise to the forest. These two myths also show the attitude of the Banjar 
people who do not blame nature, the environment, and the weather but blame themselves for ignorance of nature.

Key word: myth, dragon, taro flood, and environmental damage

\section{PENDAHULUAN}

Banjir besar melanda Kalimantan Selatan pada Januari 2021 yang meliputi sebelas kabupaten/kota, yaitu, Kabupaten Tabalong, Kabupaten Balangan, Kabupaten Hulu Sungai Utara, Kabupaten Hulu Sungai Tengah, Kabupaten Hulu Sungai Selatan, Kabupaten Tapin, Kabupaten, Banjar, Kota Banjarbaru, dan Kota Banjarmasin. (Bappelitbang banjarkab, 2021, hlm. 1) Banjir ini memberikan dampak kepada 712.129 warga, 113.420 di antaranya mengungsi, serta mengakibatkan 24 orang meninggal dan 3 orang hilang. Banjir ini merendam rumah sebanyak 122.166., 609 tempat ibadah, dan 628 sekolah. Banjir juga merusak 8.817 tambak ikan yang berada di aliran sungai. (Yulianus et al., 2021, hlm. 1)

Banjir di Kalimantan Selatan juga berdampak pada kerusakan 609 tempat ibadah, 628 sekolah, infrastruktur jalan dan memutus beberapa jembatan. (Yulianus et al., 2021, hlm. 1). Beberapa jembatan yang putus ini menyebabkan putusnya jalan yang menghubungkan antara Kabupaten Banjar dengan Kabupaten Tapin dan Kabupaten Banjar dengan Kabupaten Tanah Laut. Selain itu, banjir juga merusak lahan pertanian seluas 46.235 hektar yang mengakibatkan gagal panen akibat padi terendam selama berhari-hari (Bappelitbang banjarkab, 2021, hlm. 1)
Banjir besar pada pada tanggal 10 Januari 2021 di Kabupaten Banjar sebetulnya sudah didahului oleh banjir dengan sebaran lebih sedikit pada akhir Desember 2021. Demikian juga dengan banjir bandang di Kecamatan Hantakan pada tanggal 13 Januari 2021 yang menenggelamkan Kabupaten Hulu Sungai Tengah, didahului oleh banjir yang merendam Kecamatan Hantakan, tetapi tidak sampai ke Kota Barabai ibukota Kabupaten Hulu Sungai Tengah sekitar 14 kilometer dari Kecamatan Hantakan. Setelah Banjir besar di Kabupaten Banjar ini, ada sekitar sepuluh kali Banjir yang lebih kecil melanda Kabupaten Banjar ini.

Ada beberapa penyebab banjir besar yang melanda Kalimantan Selatan ini. Direktur Eksekutif Wahana Lingkungan Hidup Indonesia (Walhi) Kalsel Kisworo Dwi Cahyono berpendapat bahwa hilangnya hutan sekunder dan primer biasanya menjadi daerah serapan air dan digantikan dengan perkebunan sawit dan lahan tambang batu baru bara menyebabkan banjir besar melanda Kalimantan Selatan (Abdi, 2021, hlm. 1). Senada dengan pendapat ini Jaringan Advokasi Tambang (Jatam) mengemukakan adanya lubang tambang yang tidak ditutup, dan perluasan lahan tambang yang menggantikan kawasan pertanian dan ladang seluas 251.000 dan kawasan hutan seluas 464.000 (Yulianus et al., 2021, hlm. 1). KLHK mengatakan penurunan luas hutan alam di Daerah 
Aliran Sungai (DAS) Barito di Kalimantan Selatan mencapai 62,8\%, menjadi penyebab utama banjir(BBC, 2021). Namun, hal ini dibantah oleh Menteri Lingkungan Hidup dan Kehutanan (LHK) Siti Nurbaya. Menurutnya anomali cuaca merupakan penyebab utama banjir di Kalimantan Selatan. Menurut Sudharto P Hadi (Guru Besar Manajemen Lingkungan Universitas Diponegoro) tingginya curah hujan menjadi salah satu faktor penyebab banjir. Kumpulan air yang terakumulasi menjadi banjir ini dan tidak bisa diserap permukaan tanah disebabkan karena banyaknya lahan hutan yang dilalihfungsikan untuk pertambangan dan perkebunan kelapa sawit (Yulianus et al., 2021, hlm. 1). Menurut data Badan Meteorologi, Klimatologi, dan Geofisika (BMKG) tercatat curah hujan yang sangat tinggi dan ekstrem pada tanggal 10--15 Januari 2021 dengan intensitas harian berturutturut 125 milimeter (mm), $30 \mathrm{~mm}, 35$ $\mathrm{mm}, 51 \mathrm{~mm}, 249 \mathrm{~mm}$, dan 131 mm.(Yulianus et al., 2021, hlm. 1). Hal inilah yang menjadi penyebab menumpuknya aliran air yang berubah menjadi Banjir. Banjir di Kabupaten Hulu Sungai Tengah, Kabupaten Hulu Sungai Selatan, Kabupaten Banjar, Kabupaten Tanah Bumbu bermuara pada hulu sungai yang berada di kawasan Pegunung Meratus. Air bah yang mengalir mendadak ini menyebabkan sungai yang dialirinya tidak bisa menampung air. Hal ini menyebabkan banjir bandang pada daerah-daerah yang berada dekat dengan hulu sungai di Pegunungan Meratus ini, seperti banjir bandang di
Kecamatan Hantakan Kabupaten Hulu Sungai Tengah yang menghancurkan ratusan rumah dan menyebabkan beberapa orang hilang dan meninggal dibawa arus. Demikian juga banjir bandang terjadi di Kecamatan Pengaron, Kabupaten Banjar yang merupakan daerah hulu sungai dari Sungai Martapura. Isu kerusakan lingkungan, baik hutan maupun sungai sebagai daerah serapan dan aliran air menjadi isu utama penyebab banjir ini. Isu kerusakan lingkungan sebetulnya sudah menjadi isu yang menyebabkan keresahan dunia seperti perubahan lingkungan akibat revolusi industri. (Davies, 2018, hlm. 1)

Selain beberapa penyebab di atas, ada beberapa mitos yang muncul di masyarakat, baik itu muncul dalam percakapan di masyarakat, maupun lewat media sosial seperti whatapp dan facebook berkaitan dengan penyebab banjir ini, seperti mitos naga dan mitos keladi.

Ada beberapa kajian dan penelitian yang meneliti mitos dan banjir ini; Hastuti H \& Rahmawati N mendeskripsikan kecendikiaan lokal suku Moronene di Kabaena dalam Mitos Martandu dalam kaitannya dengan potensi banjir di Sungai Lakambula (Hastuti \& Rahmawati, 2020); Dhea Andini A.\& Utami R. mengungkap penanggalan dalam naskah yang berhubungan dengan hujan, kemarau, dan mitos (Dhea Andini \& Utami, 2021). Mitos hutan yang terabaikan sehingga penjadi penyebab banjir besar pernah terjadi di Hutan Wonosadi (Ahsan Nurhadi, Bakti Setlawan, 2012). Banjir besar merupakan bagian dari mitologi 
asal usul dunia di daerah nusantara (Munandar, 2012); Santosa membanding antara sajak "Hanya Satu" Amir Hamzah dan sajak "Kapal Nuh" Subagio Sastrowardojo banjir yang bercerita tentang banjir besar dan mitosnya(Santosa, 2012). Mitos juga berhubungan dengan pembentukan karakter pencinta lingkungan seperti dalam fable ikan dan burung (Afandi et al., 2019). Mitos juga berperan dalam menciptakan keseimbangan alam (Lestari et al., 2020).

Kajian ekokritik dalam karya sastra telah banyak dilakukan, misalnya kajian ekokritik dalam cerpen pernah dilakukan oleh (Trisnawati, 2014), (Igayanti et al., 2019), (Nur'aini \& Sukmawan, 2019), (Juanda \& Ramly, 2019b), (Juanda, 2018), (Juanda \& Ramly, 2019a), (Firmansyah \& Turahmat, 2019), (Juanda \& Azis, 2018), (Syamil et al., 2020), (Wijanarti, 2019), (Ikhwan, 2020). Ada juga kajian eko kritik dalam cerita rakyat (Lisnasari \& Sukmawan, 2016), teater (Martin \& O'Malley, 2020) dan puisi (Rawashdeh \& Zuraikat, 2018),(Iskarna et al., 2020), (Aris, 2020), (Mantiri \& Handayani, 2020), mitos (Lestari et al., 2020), (Herbowo, 2020).

Penelitian-penelitian di atas menunjukkan adanya isu-isu lingkungan seperti perusakan habitat dan pencemaran air (Setyowati, et al. 2020, hlm. 38), (Dewi, 2015, hlm. 376); (Firmansyah \& Turahmat, 2019, hlm. 101) perusakan hutan, bencana alam seperti longsor di bukit tambang emas (Juanda, 2018, hlm. 165).

Salah satu cara agar kerusakan lingkungan berkurang adalah dengan melakukan penyadaran hal ini bisa dilakukan dengan mengajarkan pada anak didik tentang tema dan tokoh penyeru penyelamat lingkungan (Trisnawati, 2014, hlm. 213), atau dengan pengungkapan bentuk satire dipilih agar muncul kesadaran untuk menjaga kelestarian alam (Mantiri \& Handayani, 2020, hlm. 1). Selain itu, kepercayaan masyarakat terhadap kehadiran mitos (urang bunian) secara tidak langsung berdampak terhadap perilaku masyarakat dalam menjaga dan melestarikan sumber daya alam (Herbowo, 2020, hlm. 64).

Seharusnya karya sastra berperan dalam pelestarian lingkungan (Martin \& O'Malley, 2020, hlm. 377) dan menciptakan lingkungan yang layak huni (Rawashdeh \& Zuraikat, 2018, hlm. 47). Pelestarian hutan dan kesadaran ekologi dalam bentuk mitologi harus tetap dilestarikan sebagai bentuk dari pelestarian alam dan upaya mencegah bencana banjir. Sastra bisa melakukan kampanye isu-isu lingkungan melalui pendidikan karakter dalam karya sastra (Trisnawati, 2014, hlm. 213); (Mantiri \& Handayani, 2020, hlm. 1); (Susilo, 2017, hlm. 1)(Afandi \& Juanda, 2020, hlm. 136).

Penelitian ini akan membahas mitos dan banjir yang terjadi di Kalimantan Selatan. Penelitian ini berbeda dengan yang dilakukan oleh Herbowo, (2020) dan Lestari et al., (2020). Herbowo, (2020) mengkaji mitos dalam cerpen, sedangkan Lestari et al., (2020) dalam film Aquaman. Penelitian ini akan menguraikan mitos yang muncul pada saat banjir besar pada bulan Januari 20221, hubungan antara banjir (lingkungan) dan mitos ini, dan penyebab munculnya mitos-mitos ini 
Serta bagaimana pengaruhnya kepada masyarakatnya.

\section{KERANGKA TEORI}

Studi yang mengkaji relasi antara karya sastra dan alam disebut ekokritik (Glotfelty and Fromm, 1996, hlm. xviii). Permasalahan polusi, hutan belantara, bencana, permukiman, binatang, bumi merupakan fokus dalam kajian ekokritik Greg Garrard (Garrard, 2004, hlm. 2). Dalam pengertian lebih luas ekokritik dapat membantu menentukan, mengeksplorasi, dan menyelesaikan masalah lingkungan (Garrard, 2004, hlm. 75). Kajian ekokritik menghubungkan antara karya sastra dengan lingkungan fisik, pertumbuhan populasi, hilangnya hutan liar dan belantara, kepunahan spesies hewan dengan cepat, serta peningkatan polusi dan kontaminasi udara, air, dan tanah di bumi (Love, 2003, hlm. 1).

Sukmawan, Setiawati, Rizal, \& Febriani (2020) meneliti foklor UnanUnan Tengger menegaskan bahwa manusia dan alam adalah saling berkaitan (hlm. 60). Sejalan dengan pandangan Arifiyani(Arifiyani, 2018) dan Maruti (Maruti, 2020) mengenai relasi manusia dan alam. Hal itu dipertegas oleh Glotfelty dan Fromm(Glotfelty \& Fromm, 1996, hlm. xviii) manusia dan lingkungan fisik sama-sama memiliki kepentingan sah (legitimasi). Melalui ekokritik, teks yang dikombinasikan dengan bahan bacaan, ceramah, dan diskusi memiliki dampak signifikan pada pembaca dan dunia pada umumnya sehingga dapat menggerakkan (Schneider-Mayerson, Weik von Mossner and Małecki, 2020, hlm. 327). Studi ekokiritik diharapkan dapat mewujudkan tindakan nyata dalam upaya pelestarian alam (Syamil, Yasa and Sriasih, 2020, hlm. 39).

Menurut Garrard (2004) ekokritik adalah ulasan perihal sastra dan lingkungan. Ekokritik mengambil pendekatan yang berpusat lingkungan. Ekokritik menghubungkan antara manusia dengan segala bidang budaya dan juga sebagai sikap kritis gerakan lingkungan. Garrard (Endraswara, 2016) menyatakan bahwa fokus ekokritik sastra adalah mengeksplorasi cara-cara mengenai bagaimana membayangkan dan menggambarkan hubungan antara manusia dan lingkungan dalam segala bidang sebagai hasil budaya. Fokus Garrard tersebut berusaha menelusuri perkembangan gerakan dan mengeksplorasi konsep-konsep yang terkait tentang ekokritik sastra, terkait dengan hal ihwal sebagai berikut: (1) pencemaran (pollution), (2) hutan belantara (wilderness), (3) bencana (apocalypse), (4) perumahan/tempat tinggal (dwelling), (5) binatang (animals), (6) bumi (earth). Dari eksplorasi ini, jadi fokus ekokritik sastra tetap pada alam dan lingkungan (hlm. 40).

Penelitian ini akan menggunakan teori Garrard yang menghubungkan antara karya sastra (dalam hal ini mitos) dengan pencemaran, hutan belantara, bencana, tempat tinggal, binatang, dan bumi.

\section{METODOLOGI PENELITIAN}

Pada metode penelitian akan diurai secara spesifik mengenai jenis penelitian, sumber data, populasi, sampel, teknik 
pengumpulan data, teknik analisis data, dan teknik penyajian.

Jenis penelitian ini adalah penelitian kualitatif deskriptif. Penelitian difokuskan mitos yang muncul pada saat banjir besar di Kalimantan Selatan pada bulan Januari 2021.

Data dikumpulkan dengan menggunakan metode simak dan catat. Metode simak digunakan untuk menyimak cerita yang berhubungan dengan mitos dan banjir. Sumber data dalam penelitian ini adalah seorang guru di SDN 1 Hantakan desa Hantakan, kecamatan Hantakan, Kabupaten Hulu Sungai Tengah, dan Ida warga Desa Pengaron, Kecamatan Pengaron, Kabupaten Banjar, Aliman Syahrani seorang sastrawan di Kabupaten Hulu Sungai Selatan, dan Dalang Wadiman di desa Pantai Hambawang Kabupaten Hulu Sungai Tengah. Kecamatan Hantakan Kabupaten Hulu Sungai Tengah dan Kecamatan Pengaron Kabupaten Banjar dijadikan sumber data karena menjadi tempat banjir bandang pada Januari 2021. Selain itu, peneliti juga mencari data dari media social seperti youtube.

Data yang didapat dari sumber data dan media sosial kemudian dicari sumber mitosnya dari sastra lisan di Kalimantan Selatan.

Data-data yang terkumpul tadi kemudian dipilah dan diklasifikasi berdasarkan kesamaan data. Setelah itu, data dianalisis dengan menggunakan teori Garrard, yaitu dengan menggunakan konsep ekokritik yang berhubungan dengan pencemaran, hutan belantara, bencana, tempat tinggal, binatang, (6) bumi.
Hasil analisis data ini kemudian dideskripsikan dan dianalisis pengaruh dan hubungannya dengan masyarakatnya.

\section{HASIL DAN PEMBAHASAN}

\subsection{Mitos-Mitos yang Muncul pada Saat Bencana Banjir}

Ada dua mitos yang muncul pada saat banjir besar melanda Kalimantan Selatan. Dua mitos ini, yaitu mitos naga dan mitos keladi. Mitos naga ini muncul di beberapa tempat seperti di daerah Hantakan, Kabupaten Hulu Sungai Tengah dan Kecamatan Pengaron, Kabupaten Banjar. Mitos naga di Kecamatan Hantakan berasal dari perkataan salah satu penduduk suku Dayak Meratus di Desa Datar Ajab, Kecamatan Hantakan, Kabupaten Hulu Sungai Tengah. Diisukan bahwa banjir ini muncul sebagai jalan untuk naga turun dari Pegunungan Meratus ke laut melewati Sungai Barabai. Turunnya naga ini untuk mempersiapkan perkawinan atau dengan istilah banjar 'naganya kawin'. Turunnya naga ini tidak hanya sekali, tetapi dua kali. Turunnya yang pertama untuk persiapan perkawinan, sedangkan turunnya yang kedua untuk perkawinannnya. Adapun isu yang muncul di Kecamatan Pengaron, Kabupaten Banjar adalah ada seseorang yang melihat naga turun sebelum banjir terjadi dari Perbukitan Meratus di daerah Pengaron melalui sungai yang berwarna kuning pekat.

Mitos naga berkaitan dengan cerita rakyat di Kalimantan Selatan tentang Asal Mula Sungai Barito cerita Legenda Lok Sinaga, Lok Laga, dan Tradisi 
Mengarak Kepala Naga. Cerita asal mula sungai Barito ini merupakan cerita rakyat di Kabupaten Marabahan, sedangkan cerita Legenda Lok Sinaga berasal desa Lok Loa Kandangan Kabupaten Hulu Sungai berasal dari dan legenda Lok Laga Desa Sungai Harang, Kecamatan Haruyan Kabupaten Hulu Sungai Tengah. Tradisi mengarak kepala naga dilakukan di Kabupaten Hulu Sungai Tengah.

\section{Cerita Asal Mula Sungai Barito}

Cerita asal mula sungai Barito menceritakan Bari dan Ito kucingnya, serta Naga. Diceritakan ada sepasang suami istri yang tidak mempunyai anak. Pada suatu hari si istri bermimpi bertemu dengan pertapa dan akan diberi anak dengan syarat pada saat berumur sepuluh tahun anak itu akan diambil kembali oleh pertapa tersebut. Si istri menyanggupi permintaan pertapa. Tak lama kemudian si istri melahirkan seorang anak yang diberi nama Bari. Bari mempunyai seekor kucing kesayangan yang bernama Ito.Setelah berumur sepuluh tahun Bari bersama Ito terjatuh ke dalam jurang yang berada di dekat desa dan dimakan oleh pertapa yang berwujud naga. Jatuhnya Ito ini sebagai perjanjian yang telah ditetapkan dahulu. Pengorbanan Bari dan Ito dibayar dengan dijadikannya jurang pemisah desa menjadi sungai yang akhirnya diberi nama Sungai Barito.

\section{Legenda Lok Sinaga dan Lok Laga}

Dicertikan bahwa ada sebuah keluarga pencari ikan di daerah Hulu Sungai Selatan dengan cara memasang tangguk besar. Pada suatu hari mereka mendapatkan telor besar di tangguk mereka. Walaupun sudah dibuang beberapa kali, telor besar itu terus masuk Kembali ke tangguk besar mereka. (versi yang lain menceritakan bahwa hari itu mereka tidak menemukan ikan sama sekali, tetapi melihat ada telor besar). Telor itu kemudian dibawa ke rumah. Telor itu akhirnya direbus dan dimakan oleh si ayah (versi yang lain mengatakan telor tadi dimakan kedua orang tua tadi). Tak lama kemudian si ayah merasa ada perubahan dalam tubuhnya dan kemudian berubah menjadi naga. Si anak yang terbangun terkejut melihat ada naga di dalam rumahnya. Setelah dijelaskan barulah si anak paham bahwa naga tersebut adalah orang tuanya yang berubah menjadi naga karena memakan telur. Ternyata telur itu adalah telur naga putih yang hidup di sungai tempat mereka mencari ikan. Setiap yang memakan telur itu akan berubah menjadi seekor naga. Naga ini terjun ke dalam sungai untuk mencari naga dan sampai ke suatu liang. Naga ini kemudian berdiam di liang tersebut. Tak lama kemudian datanglah naga merah sebagai pemilik liang tersebut. Akhirnya terjadilah perkelahian antara kedua naga itu. Naga jelmaan si ayah mengalami kekalahan karena tidak memiliki taring. Naga ini akhirnya kembali ke rumah. Si Istri menyarankan agar naga meletakkan dua pisau di mulutnya sebagai pengganti taring. Naga jelmaan si Ayah ini pun setuju. Kemudian terjadilah perang tanding yang kedua. Naga merah berhasil dikalahkan dan liang di Sungai Amandit itu menjadi tempat berdiam Naga jelmaan si Ayah. ${ }^{1}$

Cerita ini (versi yang berbeda) juga dijadikan sebagai warisan budaya oleh kemdikbud kabupaten Hulu Sungai Selatan dan bisa diakses di https://warisanbudaya.kemdikbud.go.i d/? newdetail\&detailCatat=1327, 6 Juli 2021).

Cerita Lok Laga mempunyai kemiripan dengan cerita Lok Sinaga dengan latar tempat yang berbeda, yaitu di Desa Sungai Harang, Kecamatan Haruyan Kabupaten Hulu Sungai Tengah.

Selain itu, ada satu tradisi yang muncul di Kabupaten Hulu Sungai Tengah, yaitu tradisi mengarak kepala naga pada saat mengantar pengantin

1Wawancara dengan Aliman Syahrani, tanggal 15 November 2021 
pria menuju rumah pengantin wanita. Menurut dalang Wadiman (seorang dalang wayang Kulit di Kabupaten Hulu Sungai Tengah) mengarak naga ini sudah dilakukan turun-temurun sejak zaman neneknya dulu. Menurutnya, kepala naga yang dipunyai (dalang Wadiman mempunyai kepala naga yang didapatkannya dari warisan neneknya) berasal dari neneknya. Pada suatu hari, neneknya pergi mencari ikan ke arah Pagat, ditengah perjalanan muncul kepala naga di sungai itu. Menurut Dalang Wadiman, neneknya itu mendapat isyarat agar membuat kepala naga seperti yang ditemuinya di sungai dekat Kampung Pagat. Kemudian dibuatklah patung kepala naga itu. Apabila masyarakat Kabupaten Hulu Sungai Tengah mengadakan perkawinan, mereka ketika mengantar pengantin pria menuju rumah pengantin wanita (mengarak pengantin) biasanya meminjam kepala naga yag dimiliki Dalang Wadiman untuk diarak menyertai pengantin pria. ${ }^{2}$

Mitos yang kedua muncul adalah mitos tentang keladi yang banyak di tanam orang di muka rumah sebagai tanaman hias. Mitos ini muncul di beberapa media sosial seperti youtube dan whattsup. Dipercayai dalam mitos tersebut bahwa menanam keladi di muka rumah merupakan pelanggaran terhadap pamali. Hal ini disebabkan karena keladi dipercayai selalu berdoa meminta hujan. Oleh karena itu, keladi yang banyak di tanam orang di perkotaan sebagai tanaman hias

${ }^{2}$ Wawancara dengan Dalang Diman, Tanggal 13 November 2021 dipercaya mendatangkan hujan dan akhirnya hujan datang diperkotaan dengan jumlah yang besar sehingga menyebabkan banjir.

Mitos ini muncul di Youtube yang diunggah pada 15 Januari 2021 dengan judul "Gara-gara Tanaman Keladi Banyu Bedalam (Banjir) \#Prayfor KalSel."

Berikut data dari video tersebut terdapat kalimat:

"Ini kaladi ampun Nabi Ilyas asa nang ampun tumbuh-tumbuhan ulun cabuti.Ulun ampun, ulun maaf. Lakasi surutakan banyu lagi dalam. Jangan lagi didalami. Nah ulun larutakan sudah kaladinya nang ulun sayangi nangini. Kadada lagi nah. Ulun kada saying lagi nah. Jangan lagi kami ditinggalamakan banyu kaladilah. Ayuha kaladi ai. Ayu ja ikam situ berenangrenang di banyu. Sakit hati banar barataan kami singsara.

Ini keladi kepunyaan Nabi Ilyas, as. yang menjaga tumbuh-tumbuhan. Saya cabut keladi ini. Saya mohon ampun, saya minta maaf. Semoga banjir cepat surut. Jangan ditambahi lagi banjirnya. Nah, saya larutkan sudah keladinya yang saya sayangi ini ke air. Saya tidak punya keladi lagi. Saya tidak sayang (keladi) lagi nah. Jangan lagi kami ditenggalamkan banjir. Ayu keladi. Ayo kamu (keladi) berenang-renang di air. Kami sakit hati semua dan sengsara (dengan adanya banjir ini).

Kondisi: seorang perempuan sedang melarutkan sebatang keladi kecil ke dalam air.

Dalam video ini muncul komentar : 'ujar urang bahari jua, "Amun membawa tanaman keladi ke rumah sampai sekampung atau sebanuaan, akan terjadi banjir besar karena tanaman keladi selalu meminta hujan 
diturunkan hujan". Han kada salah pepadahan urang bahari.

‘Ujar orang tua dulu, "Kalau membawa tanaman keladi ke rumah sampai sekampung atau satu daerah, akan terjadi banjir besar karena tanaman keladi selalu meminta hujan, maka diturunkan hujan. Ternyata nasehat orang tua dulu tidak salah.

\subsection{PEMBAHASAN}

Mitos naga merupakan refleksi yang muncul dari kebudayaan Banjar. Munculnya mitos naga dalam banjir ini tentu berkaitan dengan mitos naga Asal Mula Sungai Barito dan Legenda Lok Sinaga. Keterkaitannya itu adalah adanya kepercayaan bahwa ada mahluk penjaga sungai yang bernama naga.

Banjir di Kalimantan Selatan dimulai dengan adanya banjir bandang di hulu sungai Sungai Riam Kiwa di kaki Perbukitan Meratus daerah Pengaron. Sungai Riam Kiwa merupakan anak Sungai Martapura. Banjir bandang ini kemudian memenuhi Sungai Martapura yang menyebabkan banjir besar di Kabupaten Banjar. Sungai Martapura sendiri merupakan anak Sungai Barito. Banjir bandang di Kecamatan Pengaron ini ditandai sebelumnya dengan adanya orang yang melihat naga turun dari perbukitan menuju Sungai Martapura dan berakhir di Sungai Barito yang merupakan muara Laut Jawa. Demikian juga dengan banjir di Kabupaten Hulu Sungai Tengah dan sebagaian Hulu Sungai Selatan, yang diawali banjir di kaki Pegunungan Meratus di hulu Sungai Barabai dan hulu Sungai Amandit. Banjir di hulu Sungai Barabai merupakan banjir bandang di
Kecamatan Hantakan yang menghancurkan ratusan rumah yang menyebabkan Kota Barabai, ibukota Kabupaten Hulu Sungai Tengah terendam sampai tiga meter lebih. Kedua sungai ini merupakan anak Sungai Negara atau Sungai Bahan yang bersambungnya dengan Sungai Barito di Muara Bahan (kota Marabahan). Sungai Negara merupakan anak Sungai Barito.

Berbeda dengan mitos naga yang ada di Kecamatan Pengaron yang muncul sebelum terjadi banjir, mitos naga di Kecamatan Hantakan muncul sesudah banjir bandang terjadi dan naga itu akan turun lagi untuk melakukan perkawinan.

\subsubsection{Makna Mitos}

\subsubsection{Makna mitos naga}

Naga sebagai simbol merefleksikan juga budaya masyarakat di Kalimantan Selatan. Masyarakat Dayak di Kalimantan percaya adanya binatang yang menguasai alam atas (burung Enggang) dan penguasa alam bawah (naga). Manusia hidup diantara dua kekuasaan alam tersebut. (Yulianto, 2016, hlm. 181--182). Naga sebagai mahluk yang memiliki badan yang besar memerlukan air sungai yang besar agar bisa berjalan dari atas bukit Pegunungan Meratus sampai ke muara sungai dan ke Laut Jawa. Kondisi ini menyebabkan munculnya banjir sebagai wahana jalan agar naga bisa berjalan ke Laut Jawa. Mitos naga yang bisa dilihat di Kecamatan Pengaron dari bawah bukit menunjukkan bahwa sungaisungai di daerah tersebut tidak lagi di selimuti oleh hutan-hutan di 
pinggirannya sehingga sungai-sungai itu bisa terlihat dari bawah bukit. Atau dengan kata lain, bentuk-bentuk lekukan sungai yang berkelok-kelok seperti naga sekarang bisa dilihat dengan mudah dari bawah bukit karena sudah tidak ada lagi hutan yang menyelimutinya. Mitos naga bisa juga dimaknai dengan simbol dari penguasa dan pengusaha yang mengeruk hasil bumi Pegunungan Meratus dengan cakar bulldozer dan menghancurkan hutannya dan menggantinya dengan perkebunan kelapa sawit yang tidak menyerap air. Dengan demikian, pada akhirnya hutan akan rusak, dan tidak bisa menyerap air lagi dan banjir akan datang ke daerah tersebut, sedangkan makna naga akan turun kembali jika dikaitkan dengan makna di atas adalah bahwa banjir akan datang kembali dengan skala yang lebih besar atau minimal sama dengan banjir yang terjadi pada awal Januari 2021 ini. Oleh karena itu, masyarakat diminta bersiap-siap dalam menghadapi banjir tersebut.

Dalam hal ini dapat disimpulkan bahwa makna naga ini mencakup dua hal; naga sebagai pertanda akan banjir dan naga sebagai penyebab banjir.

Munculnya mitos naga merupakan kritik sosial terhadap kondisi Pegunungan Meratus. Ekspolitasi yang berlebihan terhadap Pegunungan Meratus dengan pertambangan dan perkebunan sawit yang masif menyebabkan munculnya permasalahan banjir. Bencana banjir ini membuat masyarakat yang terkena dampak kehilangantempat tinggal, hilangnya tempat tinggal bagi binatang lokal dan banyaknya sampah kayu yang dalam bahasa lokal disebut raba (yang merupakan asal usul dari Kota Barabai \{kota yang banyak raba\}). Ini sesuai dengan ekokritik yang disampaikan Garrad yang berkaitan dengan (1) pencemaran (pollution), (2) hutan belantara (wilderness), (3) bencana (apocalypse), (4) perumahan/tempat tinggal (dwelling), (5) binatang (animals), (6) bumi (earth)( dalam Endraswara, 2016, hlm. 40).

\subsubsection{Makna Mitos Keladi}

Keladi merupakan tanaman tumbuhan berumbi, daunnya lebar berbentuk hati, umbinya di beberapa daerah merupakan bahan makanan pokok; seratah; talas (Colocasia esculenta) (Tim Penyusun KBBI, 2016). Sebelum banjir terjadi, masyarakat Banjar sedang mengalami demam tanaman. Tanaman yang paling dicari pada waktu itu adalah keladi. Ternyata hal ini bertentangan dengan mitos yang dipercayai bahwa apabila membawa keladi hutan ke rumah akan menyebabkan banjir besar. Banjir besar itu ternyata terjadi hampir menenggelamkan seluruh tanah di Kalimantan Selatan. Oleh karena itu, agar banjir cepat surut, seorang ibu melarutkan keladi yang disayanginya ke sungai sambil meminta maaf kepada Nabi Yahya (menurut orang Banjar, penguasa air adalah Nabi Kahidir as, penguasa tanaman adalah Nabi Yahya as) dengan harapan banjir segera surut.

Mitos ini juga merupakan kritik sosial terhadap kondisi masyarakat dan kondisi alam di Kalimantan Selatan. Demam tanaman hias seperti keladi membuat orang berlomba-lomba mencari dan menjual keladi hutan yang 
berbentuk antik dan menarik. Hal ini menyebabkan adanya perambahan hutan skala kecil. Lalu bagaimana dengan perambahan hutan skala besar? Kayu Ulin, Sengon, Meranti, dan Sungkai yang diambil dan dijual dipasaran untuk dijadikan tempat tinggal dan bangunan lainnya. Apalagi dengan perubahan fungsi hutan secara masif dari hutan alam menjadi perkebunan sawit dari hutan alam menjadi lubang-lubang raksasa bekas tambang. Perusakan hutan di Pegunungan Meratus ini menyebabkan penyangga banjir pada musim hujan tidak berfungsi secara baik, bahkan mungkin sudah kehilangan fungsinya.

Kalau membawa tanaman keladi ke rumah bisa membuat satu daerah kebanjiran. Bagaimana kalau hutannya berubah menjadi lubang-lubang tambang sebagai menara air dan berubah fungsi menjadi perkebunan sawit, mungkin nanti Kalimantan akan tenggelam. Inilah kritik yang disampaikan dalam mitos keladi ini. Memperlakukan hutan secara adil dengan memosisikan hutan sesuai dengan fungsinya dan tidak mengubah fungsinya.

Isu perusakan hutan, mengubah fungsi hutan dengan meletakkan keladi di rumah yang mengakibatkan bencana longsor senada dengan hasil penelitian yang dilakukan oleh Setyowati, et al. (2020, hlm. 38), Dewi (2015, hlm. 376); Firmansyah \& Turahmat (2019, hlm. 101); danJuanda (2018, hlm. 165).

\subsubsection{Hubungan antara Mitos dan Masyarakat.}

Ada perdebatan tentang penyebab banjir antara para ahli dan seperti saling menyalahkan. Menurut beberapa ahli, banjir disebabkan karena hilangnya hutan sebagai daerah serapan air yang digantikan oleh lahan tambang dan perkebunan sawit (Abdi, 2021, hlm. 1)., serta penurunan luas hutan alam di DAS Barito(BBC, 2021). Hal ini yang dibantah oleh Menteri Lingkungan Hidup dan Kehutanan (LHK). Menurutnya anomali cuaca merupakan penyebab utama banjir ini (Yulianus et al., 2021, hlm. 1).

Menyikapi hal ini orang Banjar dengan kesantuyannya menyiratkan bahwa banjir ini tidak disebabkan oleh hilangnya hutan di Pegunungan Meratus, banyaknya lahan tambang, banyaknya hutan yang berubah fungsi menjadi perkebunan sawit, anomali cuaca dan tinggi dan ekstremnya curah hujan yang melanda hampir seluruh wilayah Kalimantan Selatan. Namun, banjir besar yang melanda wilayah Kalimantan Selatan ini disebabkan oleh naga yang turun ke Laut Jawa dan disebabkan karena tanaman keladi yang banyak menghiasi rumah di kota-kota dan kabupaten di Kalimantan Selatan.

Sebagai orang Islam (orang Banjar identik dengan Islam), urang Banjar mengetahui secara yakin bahwa kerusakan di bumi ini adalah akibat perbuatan manusia (QS. Ar-Rum: 14). Oleh karena itu, urang Banjar tidak menyalahkan alam, lingkungan, dan anomali cuaca, tetapi justru menyalahkan diri sendiri sebagai 
manusia (karena memindahkan tanaman yang mestinya berada di hutan ke rumah) dan naga (mitos) Hal ini merupakan sikap orang Banjar yang dalam kondisi apa pun selalu bersikap 'syukur' dan tidak menyalahkan orang lain. Namun, dibalik itu ada pesan yang ingin disampaikan, yaitu banjir sudah melanda bumi Kalimantan Selatan, mari bahu-membahu, bantu-membantu menanggulangi bencana banjir ini dan di masa yang akan datang banjir seperti ini tidak datang lagi dengan tidak lagi mengubah fungsi hutan, dan tidak lagi bersikap tidak adil terhadap alam dan hutan.

Mitos naga dan mitos keladi ini harus tetap dijaga sebagai pelestarian hutan (mitos naga) dan kesadaran ekologi (mitos) keladi dan juga sebagai upaya mencegah bencana banjir terjadi lagi di Kalimantan Selatan. Dengan kata lain, mitos dan cerita-cerita rakyat berperan dalam pelestarian alam dan lingkungan (Martin \& O'Malley, 2020, hlm. 377; Trisnawati, 2014, hlm. 213; Mantiri \& Handayani, 2020, hlm. 1; Susilo, 2017, hlm. 1; Afandi \& Juanda, 2020, hlm. 136). Selain itu, harus ada literasi dan pengelolaan terhadap mitos ini sehingga tidak menimbulkan efek negatif. Efek negatif ini muncul karena tidak adanya literasi terhadap mitos ini. Hal ini misalnya terjadi di daerah Hantakan, karena adanya mitos naga akan turun lagi atau dengan kata lain banjir besar akan datang lagi, maka ketika terjadi hujan lebat pada selasa malam 24 Februari 2021, hampir seluruh warga Kecamatan Hantakan keluar dari rumah menuju ke tempat yang lebih tinggi karena takut akan terjadi banjir besar lagi. Efek negatif seperti ini seharusnya tidak terjadi.

\section{PENUTUP}

\section{Simpulan}

Ada dua mitos yang muncul pada saat banjir di Kalimantan Selatan, yaitu mitos naga dan mitos keladi. Mitos naga dan mitos keladi merupakan refleksi kebudayaan Banjar yang berkaitan dengan isu lingkungan. Mitos naga merupakan kritik sosial terhadap kondisi Pegunungan Meratus yang sudah memprihatinkan. Selain itu, mitos keladi merupakan kritik untuk tidak mengubah fungsi hutan. Kedua mitos ini juga menunjukkan sikap urang Banjar yang tidak menyalahkan alam, lingkungan, dan cuaca, tetapi menyalahkan diri sendiri karena tidak mampu merawat alam. Kedua mitos ini juga membawa pesan untuk saling bahumembahu dalam menanggulangi dan tidak sibuk mencari siapa yang salah dan siapa yang mengakibatkan banjir.

\section{DAFTAR PUSTAKA}

Abdi, A. P. (2021). Sawit, Tambang, dan Penggundulan Hutan Biang Bencana di Kalsel Baca selengkapnya di artikel "Sawit, Tambang, dan Penggundulan Hutan Biang Bencana di Kalsel", https://tirto.id/f9nu.

https://tirto.id/sawit-tambang-danpenggundulan-hutan-biang-bencanadi-kalsel-f9nu, https:/ / tirto.id/sawit-tambangdan-penggundulan-hutan-biangbencana-di-kalsel-f9nu

Afandi, I., Juanda, \& Amir, J. (2019). Fabel online sebagai sarana edukasi bagi anak (Analisis nilai pendidikan 
karakter). Pangadereng: Jurnal Hasil Penelitian Ilmu Sosial dan Humaniora, 5(2), 207-224 https://doi.org/https://doi.org/10 .36869/ pjhpish.v5i2.38

Afandi, I., \& Juanda, N. (2020). Fenomena Lingkungan dalam Cerpen Daring Melalui Tanggapan Mahasiswa Pendidikan Bahasa Dan Sastra Indonesia (Studi Ekokritik). UNDAS: Jurnal Hasil Penelitian Bahasa dan Sastra, 16(2), 119-140. https://doi.org/10.26499/und.v16i 2.2713

Ahsan Nurhadi, Bakti Setlawan, B. (2012). Kearifan Lingkungan dalam Perencanaan dan Pengelolaan Hutan Wonosadi Kecamatan Ngawen Kabupaten Gunungkidul. J. Manusia dan Lingkungan, Vol. 19, No. 3 November 2012, 19(3), 226-237.

Arifiyani, F. (2018). Novel Aroma Karsa karya Dee Lestari (Kajian ekokritik Greg Garrard). Jurnal Sapala, 5(1), 111.

Aris, Q. I. (2020). Ekokritik sastra dalam puisi Talang di Langit Falastin karya Dheni Kurnia. Jurnal Ilmu Budaya, 16(2), 98-109.

Bappelitbang banjarkab. (2021). Dampak Banjir di Kabupaten Banjar, Bappeda Litbangda Rilis Kajian Cepat Penilaian Kerusakan dan Kerugian, Berikut Datanya. http:/ / bappelitbang.banjarkab.go.i d/index.php/2021/02/dampakbanjir-di-kabupaten-banjarbappeda-litbangda-rilis-kajiancepat-penilaian-kerusakan-dankerugian-berikut-datanya/. http:/ / bappelitbang.banjarkab.go.i d/index.php/2021/02/dampakbanjir-di-kabupaten-banjarbappeda-litbangda-rilis-kajiancepat-penilaian-kerusakan-dan- kerugian-berikut-datanya/

BBC, R. (2021). Banjir di Kalsel "dipicu" berkurangnya area hutan primer dan sekunder, KLHK: penurunan area hutan di DAS Barito $62,8 \%$. https://www.bbc.com/indonesia/i ndonesia-55696841.

https://www.bbc.com/indonesia/i ndonesia-55696841

Davies, J. (2018). Romantic ecocriticism: History and prospects. Literature Compass, 15(9), 1-15. https://doi.org/https://doi.org/10 .1111/lic3.12489

Dewi, N. (2015). Manusia dan Lingkungan dalam Cerpen Indonesia Kontemporer: Analisis Ekokritik Cerpen Pilihan Kompas. LITERA, 14(2). https://doi.org/10.21831/ltr.v14i2. 7211

Dhea Andini, A., \& Utami, R. R. (2021). Anggara Kasih: Hujan dalam Serat Pawarsakan dan Mitos yang Melekat di Masyarakat. Jurnal Pendidikan Indonesia, 2(4), 557-576. https://doi.org/10.36418/japendi.v $2 \mathrm{i} 4.143$

Endraswara, S. (2016). Metodologi Penelitian Ekologi Sastra. CAPS.

Firmansyah, R., \& Turahmat. (2019). Eksploitasi lingkungan dalam cerpen Di Seine meratapi Citarum melalui pendekatan ekokritik. AKSARA Jurnal Bahasa dan Sastra, 20(2), 101-108.

Garrard, G. (2004). Ecocriticism (the new critical idiom). In Routledge: Taylor and Francis Group.

Glotfelty, C., \& Fromm, H. (1996). The ecocriticism reader: Landmarks in literary ecology. University of Georgia Press.

Hastuti, H. B. P., \& Rahmawati, N. (2020). Mitos Martandu: 
Kecendekiaan Lokal Suku Moronene di Kabaena dalam Potensi Banjir di Sungai Lakambula. Kelasa, 13(2). https://doi.org/10.26499/kelasa.v1 3i2.69

Herbowo, N. A. S. (2020). Kajian Ekologi Sastra Berbasis Nilai Kearifan Lokal dalam Cerpen "Orang Bunian" Karya Gus Tf Sakai. Dialektika: Jurnal Bahasa, Sastra, dan Pendidikan Bahasa dan Sastra Indonesia, 7(1). https://doi.org/10.15408/dialektik a.v7i1.13887

Igayanti, S. A., Ekawati, M., \& Shalima, I. (2019). Interaksi Manusia dengan Alam: Tinjauan Ekokritik Sastra pada Kumpulan Cerpen Lingkungan Monyet-Monyet Tsunami Karya Sulung Prasetyo dan Implementasi Pembelajaran Sastra di SMA. Repetisi: Riset Pendidikan Bahasa dan Sastra Indoesia, 2(2), 76-88.

Ikhwan, A. K. (2020). Relasi Anak terhadap Lingkungan Hidup dalam Novel Anak Karya Anak: Kajian Ekokritik Greg Gerrard. Bapala, 7(7), 1-10.

Iskarna, T., Brameswari, C., \& Astuti, E. P. (2020). Alam dalam perspektif natives dan new settlers: Kajian ekokritik Puisi " Monolog Bumi Terjarah " dan "We Are Going ." Jurnal Ilmiah Kebudayaan SINTESIS, 14(1), 47-58.

Juanda. (2018). Fenomena eksploitasi lingkungan dalam cerpen Koran Minggu Indonesia: Pendekatan ekokritik. AKSIS Jurnal Pendidikan Bahasa dan Sastra Indonesia, 2(2), 165189.

https://doi.org/http://doi.org/10. 21009/AKSIS

Juanda, \& Azis. (2018). Pendidikan lingkungan siswa SMA dalam cerpen Koran Kompas: Pendekatan ekokritik. Prosiding Seminar Hasil Penelitian (SNP2M), 2018(3), 348352.

Juanda, \& Ramly. (2019a). Fenomena lingkungan cerpen daring koran Media Indonesia dan Suara Merdeka alternatif pengayaan materi ajar di SMP: Kajian ekokritik. Prosiding Seminar Nasional Penelitian $\mathcal{E}$ Pengabdian Kepada Masyarakat, 3743.

Juanda, \& Ramly. (2019b). Fenomena lingkungan cerpen daring koran Tempo alternatif pengayaan materi ajar di SMP: Kajian ekokritik. Prosiding Seminar Nasional LP2M UNM - 2019 "Peran Penelitian dalam Menunjang Percepatan Pembangunan Berkelanjutan di Indonesia" ISBN:, 3, 238-245.

Lestari, O. A., Sahara, R. M., Ardhini, Z. A., \& Chusna, I. (2020). Mitos dan kritik lingkungan dalam film Aquaman (2018). Buletin Al-Turas, 26(1), 85-101. https://doi.org/10.15408/bat.v26i1. 14452

Lisnasari, L., \& Sukmawan, S. (2016). Berhulu Welas Asih Pepitu, Bermuara Narasi Arkadia: Kajian Ekokritik cerita rakyat tengger. Jurnal Ilmiah Edukasi $\mathcal{E}$ Sosial, Volume, 7(2).

Love, G. A. (2003). Practical ecocriticism, literature, biology, and the environment. In University of Virginia Press.

Mantiri, G. J. M., \& Handayani, T. (2020). Bentuk-bentuk satire ekologis dalam kumpulan puisi Suara Anak Keerom (Tinjauan ekokritik). Jentera: Jurnal Kajian Sastra, 9(1), 1-14. https://doi.org/DOI: 
https://doi.org/10.26499/jentera.v9 i1.1803

Martin, R., \& O'Malley, E. (2020). EcoShakespeare in performance: introduction. SEL - Studies in English Literature, 36(3), 377-390.

Maruti, E. S. (2020). evelopment of geographical environment utilization in campursari song lyrics: An Ecolinguistic perspective. Linguista: Jurnal Ilmiah Bahasa, Sastra, dan Pembelajarannya, 4(1), 34-42. https://doi.org/http://doi.org/10. 25273/linguista.v4i1.6337

Munandar, A. A. (2012). Mitos dan peradaban bangsa. Prosiding The 4th International Conference on Indonesian Studies: "Unity, Diversity and Future," 3-23.

Nur'aini, S., \& Sukmawan, S. (2019). Bencana dan mitigasi dalam cerita pendek Siber Indonesia. Jurnal Ilmiah Edukasi \& Sosial, 10(2), 158164.

Rawashdeh, F. I., \& Zuraikat, M. J. (2018). The phenomenology of the dwelling space in Robert Frost's poetry. 3L: Language, Linguistics, Literature, 24(4), 47-56. https://doi.org/10.17576/3L-20182404-04

Santosa, P. (2012). Mimesis Kisah Nabi Nuh dalam Tiga Sajak Modern Indonesia. Salingka (Majalah ilmiah Bahasa dan Sastra), 30-42.

Schneider-Mayerson, M., Weik von Mossner, A., \& Małecki, W. P. (2020). Empirical ecocriticism: Environmental texts and empirical methods. ISLE: Interdisciplinary Studies in Literature and Environment, 2(Spring), 327-336. https://doi.org/10.1093/isle/isaa02 2

Setyowati, N., Emzir, \& Lustyantie, N.
(2020). Nature and social attitude in folklore entitled timun mas: Ecocritical study. Journal of Applied Studies in Language, 4(1), 38-47. https://doi.org/http:/ /dx.doi.org/ 10.31940/jasl.v4i1.1649

Sukmawan, S., Setiawati, E., Rizal, M. S. \& Febriani, R. (2020). Dimensi ekologi folklor Unan-Unan Tengger. Jurnal Ilmiah Edukasi \& Sosial, 11(1), 60-66.

Susilo, R. (2017). Kajian Ekologi Sastra Cinta Semanis Racun 99 Cerita Daro 9 Penjuru Dunia. Nosi, 5(5).

Syamil, I., Yasa, I. N., \& Sriasih, S. A. P. (2020). Kritik Pengarang terhadap pembalakan hutan pada novel Nyanyian Kemarau dan Tangisan Batang Pudu: Kajian ekokritik dan relevansinya terhadap pembelajaran sastra. Jurnal Pendidikan Bahasa dan Sastra Indonesia, 10(1), 29-40. https://doi.org/http:/ /dx.doi.org/ 10.23887/jjpbs.v10i1.24538

Tim Penyusun KBBI. (2016). KBBI. Badan Pengembangan dan Pembinaan Bahasa.

Trisnawati, R. K. (2014). Employing Mary Whitebird's short story Ta$\mathrm{Na}-\mathrm{E}-\mathrm{Ka}$ to raise student's ecological awareness. Jurnal Humaniora, 26(2), 213-224. https://doi.org/10.22146/jh.v26i2.5 243

Wijanarti, T. (2019). Masyarakat Dayak dan alam: Sebuah pembacaan ekokritik sastra terhadap cerita pendek "Menari di Puncak Beringin'" karya Budi Dayak Kurniawan. UNDAS: Jurnal Hasil Penelitian Bahasa dan Sastra, 15(2), 135.

https://doi.org/10.26499/und.v15i 2.1747

Yulianto, A. (2016). Makna Mitos “Asal 
Undas Vol 17, Nomor 2, Desember 2021: 227--242

Mula Sungai Barito": Sebuah Analisis Strukturalisme Levis Strauss. Suar Betang, 2(2016), 167182.

https://doi.org/https:/ / doi.org/10 .26499/surbet.v11i2.7

Yulianus, J., Triwibowo, D. R., Arif, A., \& Mustika, P. P. (2021). Banjir Besar di Kalsel, Potret Suram Kerusakan Alam.

https://www.kompas.id/baca/nusantara/ 2021/01/25/banjir-besar-kalsel-potretsuram-kerusakan-alam/, 1. https://www.kompas.id/baca/nus antara/2021/01/25/ banjir-besarkalsel-potret-suram-kerusakanalam/ 